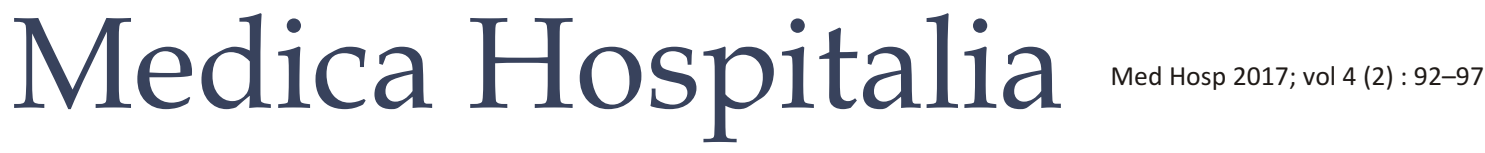

Original Article

\section{Hubungan Lingkar Lengan Atas Ibu Hamil Genap Bulan dengan Ukuran Plasenta dan Berat Bayi Lahir}

\author{
Eunike Lusiana ${ }^{1}$, Hertanto Wahyu Subagio ${ }^{2}$, Besari Adi Pramono ${ }^{3}$ \\ ${ }^{1}$ PPDS I Gizi Klinik Fakultas Kedokteran Universitas Diponegoro/RSUP Dr. Kariadi Semarang \\ ${ }^{2}$ Departemen Gizi Klinik Fakultas Kedokteran Universitas Diponegoro/RSUP Dr. Kariadi Semarang \\ ${ }^{3}$ Divisi Fetomaternal, Departemen Obstetri dan Ginekologi Fakultas Kedokteran UNDIP/RSUP Dr. Kariadi - RSND Semarang
}

\begin{abstract}
Abstrak
Latar belakang : Status gizi ibu yang tercermin dari Lingkar Lengan Atas (LILA) sangat mempengaruhi status gizi bayi terutama Berat Bayi Lahir (BBL). Malnutrisi intrauterin mengakibatkan morbiditas dan mortalitas perinatal serta terjadinya penyakit degeneratif yang dikenal dengan Foetal Origin Adult Disease (FOAD). Plasenta merupakan organ untuk mencari riwayat malnutrisi intrauterin. Penelitian ini bertujuan untuk mencari hubungan LILA ibu hamil dengan ukuran plasenta (berat plasenta dan luas plasenta) dan BBL.

Metode : Lima puluh subyek penelitian yang memenuhi kriteria inklusi dan eksklusi, diambil secara consecutive sampling, dari pasien yang melahirkan selama bulan April - Mei 2016 di RSUP Dr. Kariadi, Puskesmas Halmahera, Puskesmas Ngresep dan RSIA Bunda. Data meliputi LILA, berat plasenta, luas plasenta dan BBL. Untuk mempelajari hubungan antara variabel independen (LILA, berat plasenta dan luas plasenta) dengan variabel dependen (BBL) dilakukan analisis uji korelasi. Analisis regresi linier multiple digunakan untuk mengetahui hubungan antara seluruh variabel independen dengan dependen secara simultan.

Hasil : Ada hubungan antara LILA dengan BBL $(r=0,762$; $p=0,0001)$, berat plasenta $(r=0,673 ; p=0,0001)$ dan luas plasenta $(r=0,636 ; p=0,0001)$. Pada analisis multivariat ternyata LILA, berat plasenta dan luas plasenta secara berturut-turut berpengaruh terhadap BBL. Nilai $r^{2}=0,237$, artinya pengaruh LILA, berat plasenta dan luas plasenta terhadap BBL sebesar $23,7 \%$.

Simpulan : LILA berhubungan secara positif dengan BBL, berat plasenta dan luas plasenta.
\end{abstract}

Kata kunci : LILA, BBL, berat plasenta, luas plasenta.

\section{Relationship between mid upper arm circumference with placental size and birth weight in aterm pregnant woman}

\begin{abstract}
Background : Maternal nutritional status that reflected from Mid Upper Arm Circumference (MUAC) is greatly affect infant's nutritional status, especially birthweight. Intrauterine malnutrition resulting in perinatal morbidity and mortality as well as the occurrence of degenerative diseases, known as Fetal Origin Adult Disease (FOAD). The placenta is the organ to looking for a history of intrauterine malnutrition. The objectives of this study was to seeking a relationship between MUAC of pregnant woman with the size of the placenta (placental weight and placental area) and birth weight.

Methods : Fifty research subjects who meet the inclusion and exclusion criteria, taken by consecutive sampling from patients who gave birth during the months of April-May 2016 at Kariadi General Hospital, Halmahera Community Health Center, Ngresep Community Health Center and Bunda Maternity Hospital. Data includes MUAC, placental weight, placental area and birth weight. We do correlation analysis to study the relationship between independent variables (MUAC, placental weight and placental area) with the dependent variable (birth weight). Multiple linear regression analysis is used to determine the relationship between all independent variables and the dependent simultaneously.

Results : There is a relationship between MUAC with birth weight $(r=0.762 ; p=0.0001)$, placental weight $(r=0.673 ; p=0.0001)$ and placental area $(r=0.636 ; p=0.0001)$. On multivariate analysis turns MUAC, placental weight and placental area successively affect the birth weight. Value $r^{2}=0.237$, meaning that the effect of MUAC, placental weight and placental area of the birth weight amounted to $23.7 \%$.

Conclusion : MUAC positively associated with birth weight, placental weight and placental area.
\end{abstract}

Keywords: MUAC, birth weight, placental weight, placental area. 


\section{PENDAHULUAN}

Status gizi ibu merupakan faktor penting kesehatan yang mempengaruhi kehamilan dan bayi yang dilahirkan. ${ }^{1}$ Status gizi ibu akan mempengaruhi luaran kehamilan seperti berat badan lahir, mortalitas perinatal serta ukuran plasenta. $^{2}$ Berat badan lahir terkait dengan morbiditas dan mortalitas perinatal, sedangkan ukuran plasenta terkait dengan penyakit degeneratif pada masa dewasa seperti DM II, hipertensi dan kardiovaskuler. ${ }^{3}$

Pertumbuhan intrauterin sangat penting, tidak hanya untuk kesehatan janin dan anak tetapi juga untuk kesehatan di masa mendatang saat dewasa. ${ }^{4}$ Malnutrisi kronis intrauterin lebih berbahaya dan memiliki banyak akibat bila dibandingkan dengan malnutrisi post natal. ${ }^{5}$ Malnutrisi kronis akan mempengaruhi kapasitas metabolik, struktural dan fungsional berbagai sistem organ janin termasuk plasenta. ${ }^{6}$ Penelitian Barker menunjukkan bahwa penyebab bayi Berat Badan lahir Rendah (BBLR) adalah karena lingkungan intrauterin tidak adekuat dan berakibat timbulnya risiko menderita penyakit kronik dimasa dewasa. Lingkungan intrauterin yang tidak adekuat terjadi karena kebutuhan zat gizi janin melebihi ketersediaan plasenta ibu. Ini dikenal dengan Fetal Origin Adult Disease (FOAD). ${ }^{7}$

Berat bayi lahir merupakan indikator penting kesehatan bayi dan pertumbuhan intrauterin. Berat bayi lahir menunjukkan status gizi janin. ${ }^{8}$ Status gizi janin ditentukan oleh genetik, status gizi ibu, plasenta, penyakit kronik dan usia ibu. ${ }^{9}$ Pertumbuhan intrauterin terkait dengan status gizi ibu.Parameter yang sering dipakai untuk menilai status gizi ibu adalah LILA yang menggambarkan massa otot dan jaringan lemak subcutan. ${ }^{10}$ LILA yang rendah menunjukkan malnutrisi ibu. LILA merupakan parameter antropometri yang simpel, tidak dipengaruhi oleh udem, non invasif dan ekonomis. $^{2}$ Selain status gizi ibu, plasenta berperan penting dalam pertumbuhan janin. Plasenta merupakan kompartemen utama penentu pertumbuhan janin. Kemampuan transfer oksigen \& zat gizi plasenta tergantung dari ukuran, morfologi dan aliran darah plasenta. ${ }^{11}$

Berbagai penelitian yang ada kebanyakan mengkaitkan LILA dengan BBL. Belum ada penelitian yang secara khusus mengkaitkan LILA dengan ukuran plasenta. Penelitian ini dilakukan untuk mencari hubungan LILA dengan BBL dan ukuran plasenta. Penelitian ini bertujuan secara khusus mencari hubungan LILA dengan ukuran plasenta.

\section{METODE}

Penelitian ini termasuk jenis cross sectional dengan metode analisis korelasional karena akan mencari hubungan LILA dengan ukuran plasenta dan BBL. Penelitian ini dilakukan di RSUP Dr. Kariadi, Puskesmas
Ngresep, Puskesmas Halmahera dan RSIA Bunda pada periode April sampai dengan Mei 2016. Sampel adalah semua ibu hamil genap bulan yang memenuhi kriteria inklusi yaitu usia 20-35 tahun, kehamilan tunggal, pervaginam atau perabdominam, bayi hidup, tidak menderita penyakit kronik dan kehamilan tanpa penyulit. Data yang diambil dari ibu melahirkan berupa identitas, usia, pendidikan, peritas, usia kehamilan, kadar hemoglobin, jenis kelamin bayi, rujukan, berat badan sebelum hamil, LILA, berat bayi lahir, berat plasenta serta panjang dan lebar plasenta. Analisis data dilakukan dengan menguji normalitas dan korelasi. Normalitas data dinilai dengan uji Kolmogorov-Smirnov. Uji korelasi dilakukan dengan Pearson dan Spearman.

\section{HASIL}

Selama periode penelitian didapatkan 50 subyek penelitian dengan karakteristik tampak pada tabel 1.

Pada penelitian ini usia ibu hamil genap bulan termuda adalah 20 tahun dan tertua adalah 35 tahun dengan kategori terbanyak berusia antara 31-35 tahun (44\%). Pendidikan pasien terbanyak adalah SMA (50\%). Sebagian besar pasien bekerja (58\%). Paritas terbanyak adalah 2-3 sebesar $54 \%$. Jenis persalinan terbesar adalah pervaginam $(66 \%)$. Usia kehamilan pasien terbanyak adalah 39 minggu (36\%). BMI terbanyak adalah $\geq 23$ $(58 \%)$. Jenis kelamin bayi yang dilahirkan sama antara laki-laki dan perempuan. Sebanyak $98 \%$ pasien datang tanpa rujukan. Rerata kadar hemoglobin \pm SD adalah $11,35 \pm 1,15$ dengan $\mathrm{Hb}$ terendah adalah 8,40. Prosentase anemia pada subyek penelitian ini adalah $32 \%$. Rerata lingkar lengan ibu hamil genap bulan adalah $27,60 \pm 3,28$ dengan lingkar lengan terendah adalah $20 \mathrm{~cm}$. Ibu hamil yang menderita KEP (dengan LILA $<23,5 \mathrm{~cm}$ ) sebesar $8 \%$. Rerata berat plasenta \pm simpangan baku adalah $611 \pm$ 131,84 g dengan plasenta teringan adalah 453 g. Rerata luas plasenta bayi \pm simpangan baku adalah $309,24 \pm$ $58,35 \mathrm{~cm}^{2}$ dengan plasenta terluas dan tersempit adalah 452,16 dan $204,10 \mathrm{~cm}^{2}$. Rerata berat bayi lahir \pm simpangan baku adalah $3134,90 \pm 371,90 \mathrm{~g}$ dengan berat bayi lahir terberat dan teringan adalah 4000 dan $2200 \mathrm{~g}$. Prosentase bayi BBLR pada penelitian ini adalah $2 \%$. Gambar 1 menjelaskan prosentase BBL pada penelitian ini.

Uji korelasi antara LILA dengan berat plasenta menggunakan uji korelasi Pearson karena LILA dan berat plasenta berdistribusi normal $(p>0,05)$. Hasil uji ini terlihat dalam gambar 3 .

Hasil uji korelasi menunjukkan ada hubungan positif signifikan antara lingkar lengan atas dengan berat plasenta bayi $(r=0,673 ; p=0,0001)$. Artinya semakin besar ukuran lingkar lengan atas ibu hamil maka semakin berat plasenta bayi yang dikandung.

Uji korelasi antara LILA dengan luas plasenta menggunakan uji korelasi Pearson karena LILA dan luas 


\section{TABELL 1}

\section{Karakteristik subyek penelitian}

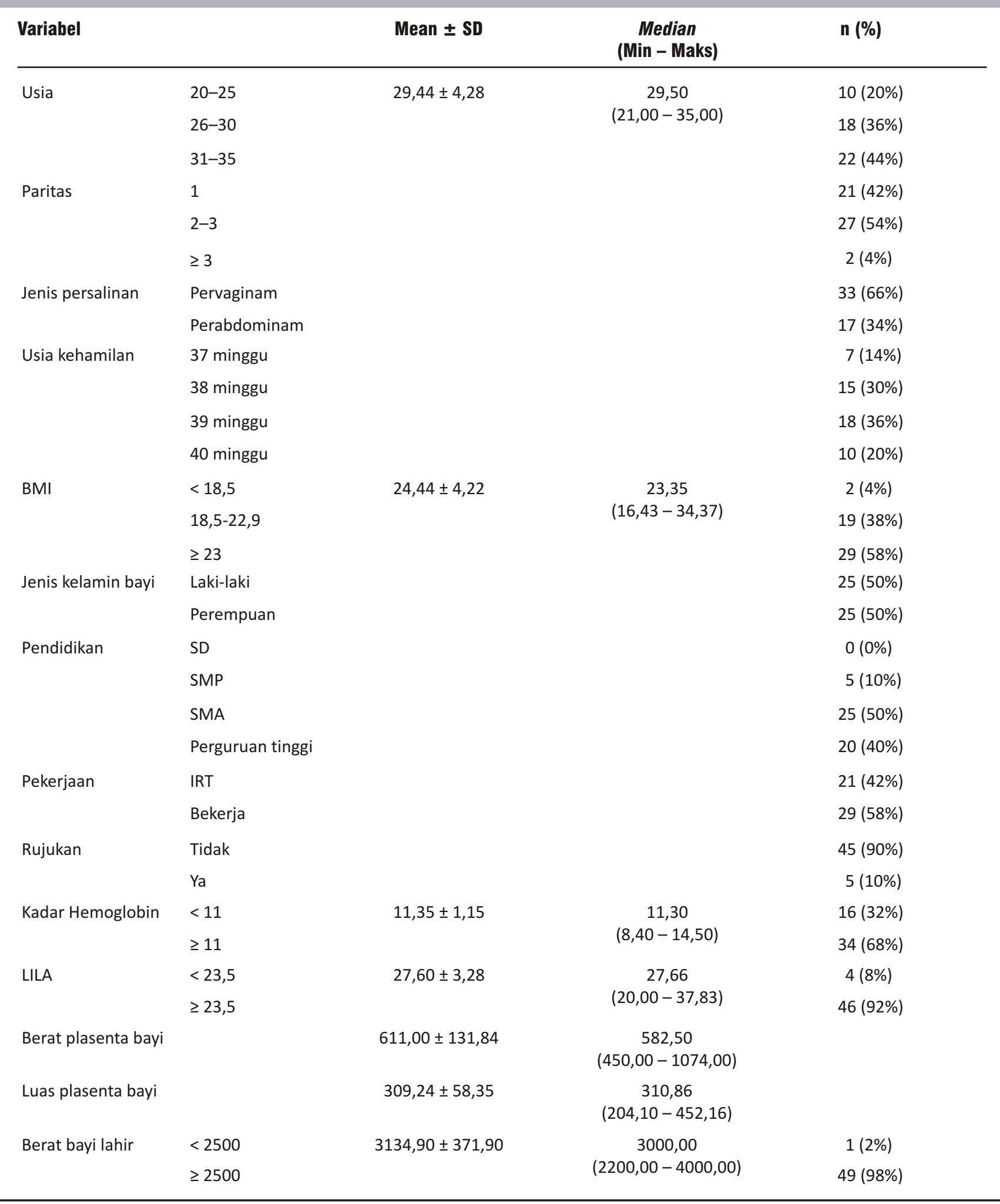

plasenta berdistribusi normal $(\mathrm{P}>0,05)$. Hasil uji ini terlihat dalam gambar 4 .
Hasil uji korelasi ada hubungan positif signifikan antara lingkar lengan atas dengan luas plasenta bayi 


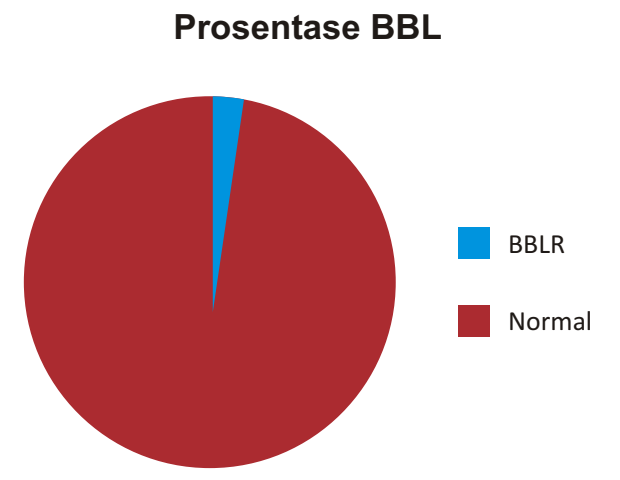

Gambar 1. Prosentase BBL pada penelitian ini

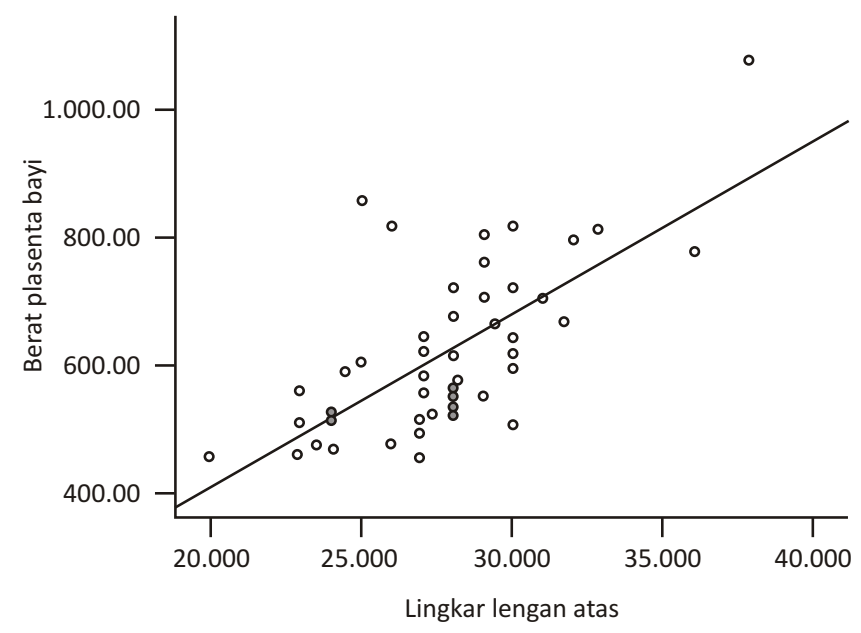

Gambar 3. Hubungan antara LILA dengan Berat Plasenta Bayi

$(\mathrm{r}=0,636 ; p=0,0001)$. Artinya semakin besar ukuran lingkar lengan atas ibu hamil maka semakin luas plasenta bayi yang dikandung.

Uji korelasi antara LILA dengan BBL menggunakan uji korelasi Rank Spearman karena LILA berdistribusi normal $(\mathrm{P}>0,05)$, sedangkan $\mathrm{BBL}$ berdistribusi tak normal $(\mathrm{P}<0,05)$. Adapun hasilnya terlihat dalam gambar 5 .

Hasil uji korelasi terdapat hubungan positif signifikan antara lingkar lengan atas dengan berat bayi lahir $(\mathrm{r}=0,762 ; p=0,0001)$. Artinya semakin besar ukuran lingkar lengan atas ibu hamil maka semakin berat bayi yang dilahirkan.

Analisis multivariat menjelaskan persamaan regresi $y=a+b 1 \times 1+b 2 \times 2+b 3 \times 3=>y=1,47+0,47$ (LILA) $+0,27(\mathrm{BP})+0,25(\mathrm{LP})$. Dari persamaan ini didapatkan $\mathrm{F}=$ 4,762 dan $p=0,006$ yang artinya terdapat korelasi signifikan antara LILA, berat plasenta, luas plasenta dengan BBL. Variabel yang paling besar kontribusinya adalah LILA. Nilai $r^{2}=0,237$, artinya pengaruh LILA, berat plasenta dan luas permukaan plasenta terhadap BBL sebesar 23,7\%.

\section{Prosentase LILA}

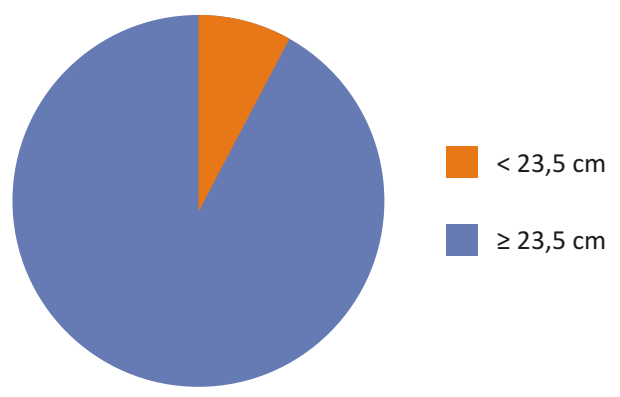

Gambar 2. Prosentase LILA pada penelitian ini

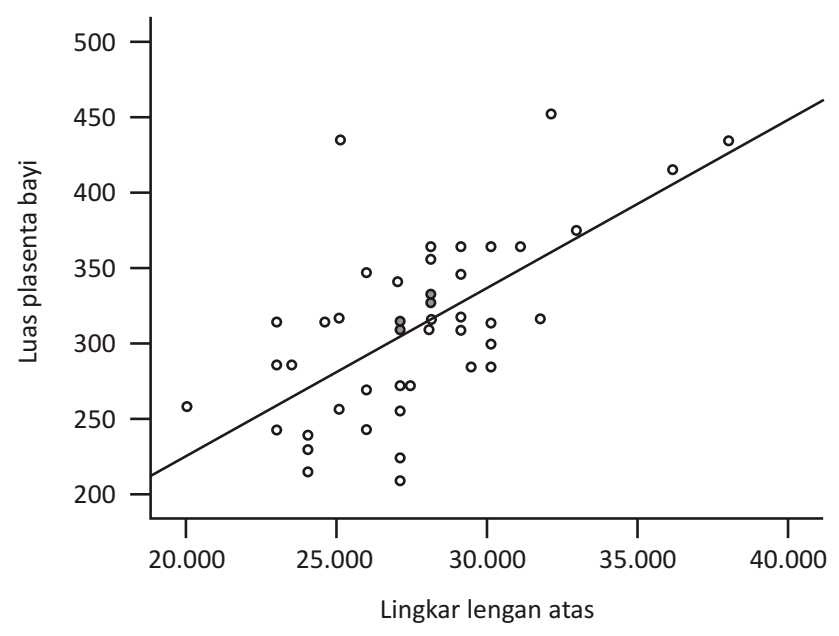

Gambar 4. Hubungan antara LILA dengan Luas Plasenta Bayi

\section{PEMBAHASAN}

Pada penelitian ini sosial ekonomi subyek penelitian cukup baik. Hal ini terlihat dari pendidikan dan pekerjaan subyek penelitian. Sebagian besar subyek penelitian berpendidikan SMA sampai perguruan tinggi dan lebih dari separuh bekerja. Jumlah paritas pada kelompok sosial ekonomi baik cenderung menurun. ${ }^{12}$ Pada penelitian ini jumlah paritas terbanyak adalah 2-3. Sebagian besar subyek penelitian memiliki BMI $\geq 23$ dan LILA $\geq 23,5$ yang berarti memiliki status gizi baik bahkan cenderung overweight dan obese. LILA merupakan indikator massa otot dan jaringan lemak subkutan. LILA menggambarkan status gizi saat ini. Status gizi ibu dinilai dengan LILA. Kadar hemoglobin subyek penelitian cukup baik. Rata-rata kadar hemoglobin masih diatas batas nilai normal wanita hamil yaitu $11 \mathrm{mg} / \mathrm{dL}$. Berbagai faktor seperti usia, paritas, sosial ekonomi, LILA dan BMI akan menentukan status gizi ibu hamil. Status gizi ibu hamil, plasenta dan kadar hemoglobin mempengaruhi berat bayi lahir yang merupakan indikator status gizi anak. ${ }^{5}$ 


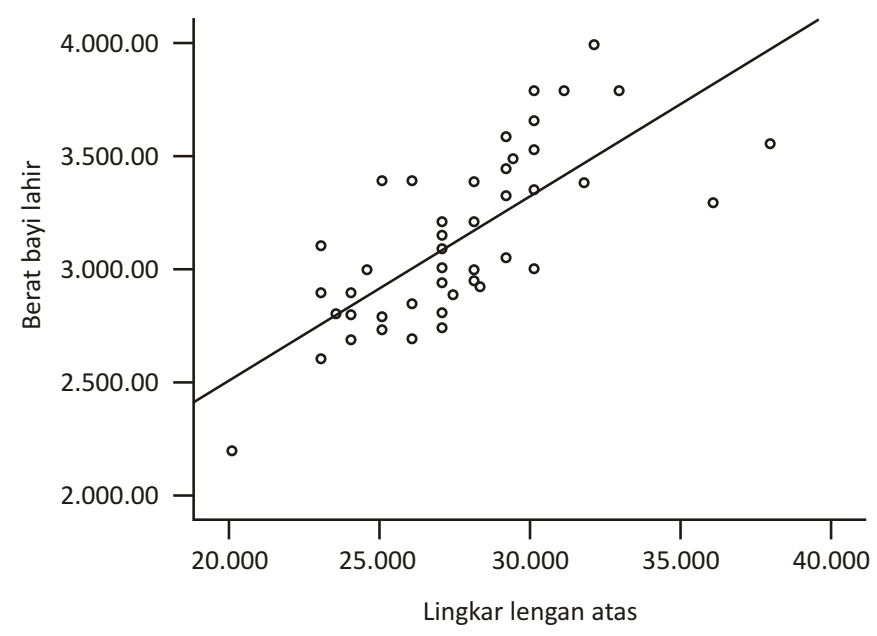

Gambar 5. Hubungan antara LILA dengan Berat Bayi Lahir

Prevalensi BBLR pada penelitian ini rendah (2\%). Ini tidak sesuai dengan prevelensi BBLR di Indonesia $(10,2 \%)$ pada tahun 2013 . Hal ini terjadi karena penelitian ini dilakukan pada subyek penelitian dengan usia optimal untuk hamil (20-35 tahun), kehamilan aterm, status gizi cukup bagus, tidak menderita penyakit kronis dan kehamilan tanpa penyulit.

Status gizi ibu hamil ditentukan oleh keseimbangan antara asupan dan utilisasi zat gizi. Kehamilan akan meningkatkan utilisasi zat gizi. ${ }^{11}$ Pertumbuhan janin terkait dengan penambahan berat badan dan perubahan komposisi tubuh ibu hamil. Penambahan lemak subcutan merupakan cadangan ibu untuk pertumbuhan janin. ${ }^{13}$ Penelitian ini sesuai dengan penelitian Winder dkk menyatakan bahwa peningkatan massa lemak ibu hamil yang menggambarkan status gizi saat ini akan meningkatkan berat dan luas plasenta. Peningkatan massa lemak ibu hamil terutama disimpan dalam bentuk jaringan lemak subcutan ekstremitas. Jaringan lemak subcutan dinilai dengan pengukuran LILA. Peningkatan jaringan lemak akan meningkatkan konsentrasi lemak dan glukosa dalam sirkulasi darah ibu. Hal ini akan berakibat peningkatan pertumbuhan, berat dan luas permukaan serta kapasitas transpor plasenta. Makin berat dan luas plasenta, maka kapasitas traspor zat gizi makin meningkat. ${ }^{14}$ Sebaliknya ibu yang kurang gizi menyebabkan defisiensi glukosa, asam amino dan asam lemak yang diperlukan untuk tumbuh kembang janin. Hal ini akan berakibat gangguan pertumbuhan plasenta, penurunan transfer zat gizi dan oksigen serta menganggu tumbuh kembang janin. ${ }^{7}$

Penambahan berat badan ibu hamil yang tidak adekuat akan menghambat pertumbuhan janin karena cadangan energi ibu tidak adekuat. ${ }^{5}$ Pembatasan energi kronis selama kehamilan terkait dengan BBLR. Ibu hamil dengan malnutrisi akan mengalami perubahan hemodinamik seperti penurunan volume ekspansi yang mengakibatkan penurunan mikronutrien dan terkait dengan hambatan pertumbuhan janin. ${ }^{9}$ Penelitian ini sesuai dengan penelitian Godhia bahwa status gizi ibu yang dinilai dengan LILA berhubungan positif bermakna dengan berat bayi lahir $(p=0,035 ; r=0,368) .{ }^{15}$ Penelitian Ferial juga menunjukkan hasil yang sama yaitu terdapat hubungan positif signifikan antara LILA dengan BBL $(p<0,05 ; \mathrm{r}=0,611)$. Ibu dengan LILA rendah $(<23,5)$ akan melahirkan bayi BBLR. ${ }^{16}$ Status gizi ibu yang adekuat diperlukan untuk pertumbuhan janin optimal. Pertumbuhan janin dinilai dari BBL. Status gizi adekuat menyediakan cadangan energi yang cukup untuk proses pertumbuhan optimal bayi. ${ }^{5}$ BBL mengambarkan pertumbuhan janin intrauterin. Pertumbuhan janin dipengaruhi oleh berbagai faktor seperti genetik, status gizi ibu, metabolisme ibu, faktor endokrin serta fungsi dan perfusi plasenta. ${ }^{17}$

Analisis multivariat menjelaskan persamaan regresi $y=a+b 1 \times 1+b 2 \times 2+b 3 \times 3=>y=1,47+0,47$ (LILA) $+0,27(\mathrm{BP})+0,25(\mathrm{LP})$. Dari persamaan ini didapatkan F= 4,762 dan $p=0,006$ yang artinya terdapat korelasi signifikan antara LILA, berat plasenta, luas plasenta dengan BBL. Variabel yang paling besar kontribusinya adalah LILA. Nilai $r^{2}=0,237$, artinya pengaruh LILA, berat plasenta dan luas permukaan plasenta terhadap BBL sebesar 23,7\%. BBL dipengaruhi oleh banyak faktor seperti genetik, status gizi, asupan, plasenta, hormonal, penyakit infeksi, penyakit kronik, obat-obatan dan usia ibu. Oleh karena itu perlu penelitian lebih lanjut untuk mencari besarnya peran variabel yang lainnya dalam mempengaruhi BBL. ${ }^{18}$

\section{SIMPULAN}

Dari penelitian ini dapat disimpulkan bahwa:

1. LILA berhubungan secara positif dengan BBL. Hal ini berarti semakin besar LILA maka BBL akan semakin meningkat.

2. LILA berhubungan secara positif dengan ukuran 
plasenta (berat plasenta dan luas plasenta). Hal ini berarti semakin besar LILA maka ukuran plasenta (berat plasenta dan luas plasenta) akan semakin besar.

3. Hasil analisis multivariat didapatkan variabel yang paling mempengaruhi BBL adalah LILA, diikuti dengan berat plasenta dan luas plasenta. Nilai $\mathrm{r}^{2}=$ 0,237 artinya LILA, berat plasenta dan luas plasenta secara bersama-sama menentukan 23,7\% BBL.

\section{DAFTAR PUSTAKA}

1. Rambouskova J, Dlouhy P, Krizova E, Prochazka B, Hrncirova D, Andel M. Health Behaviors, Nutritional Status, and Anthropometric Parameters of Roma and Non-Roma Mothers and Their Infants in the Czech Republic. J Nutr Educ Behav. 2009;41:58-64.

2. Tang AM, Dong K, Deitchler M, et al. Use of Cutoffs for MidUpper Arm Circumference (MUAC) as an Indicator or Predictor of Nutritional and Health- Related Outcomes in Adolescents and Adults: A Systematic Review. Food and Nutrition Technical Assistance III Project (FANTA). 2013.

3. Jansson T, Powell TL. Role of the placenta in fetal programming: underlying mechanisms and potential interventional approaches. Clinical Science. 2007;113:1-13.

4. Cetin I, Alvino G, Radaelli T, Pardi G. Fetal nutrition: A review. Acta Pædiatrica. 2005;94(449):7-13.

5. Kruger H. Maternal anthropometry and pregnancy outcomes: a proposal for the monitoring of pregnancy weight gain in outpatient clinics in South Africa. Curationis. 2005;28:40-49.

6. Elshibly EM, Schmalisch G. The effect of maternal anthropometric characteristics and social factors on gestational age and birth weight in Sudanese newborn infants. BMC Public Health. 2008;8(244):1-7.

7. Baptise-Robert K, M.Salafia C, Nicholson WK, Duggan A, Wang N-Y, Brancati FL. Gross placental measures and childhood growth. J Matern Fetal Neonatal Med. 2013;22(1):1323.

8. Pacce S, Saure C, Mazza CS, et al. Impact of maternal nutritional status BEFORE and during pregnancy on neonatal body composition: A Cross-sectional study. Diabetes \& Metabolic Syndrome: Clinical Research \& Reviews. 2015:1-12.

9. Singh LCG, Chouhan CR, Sidhu MK. Maternal Factors for Low Birth Weight Babies. MJAFI 2009;65:10-12.

10. Lee RD, Nieman DC. Assessment of the Hospitalized Patient, In: Nutritional Assessment, $5^{\text {th }}$ ed, Mc Graw Hill, 2010, p 221-226.

11. Grieger JA, Clifton VL. A Review of the Impact of Dietary Intakes in Human Pregnancy on Infant Birthweight. Nutrient. 2015;7:153-178.

12. Imdad A, Bhutta ZA. Nutritional Management of the Low Birth Weight/Preterm Infant in Community Settings: A Perspective from the Developing World. The Journal of Pediatric. 2013;162:S107-114.

13. Gernand AD, Christian P, Paul RR, et al. Maternal Weight and Body Composition during Pregnancy Are Associated with Placental and Birth Weight in Rural Bangladesh. J. Nutr. 142. 2012;142:2010-2016.

14. Winder NR, Krishnaveni GV, Veena SR, et al. Mother's lifetime nutrition and the size, shape and efficiency of the placenta. Placenta. 2011;32:806-810.

15. Godhia M, Nigudkar M, Desai R. Associations Between Maternal Nutritional Characteristics and the Anthropometric Indices of Their Full-term and Pre-term Newborns. Pakistan Journal of Nutrition. 2012;11(4):343-349.

16. W.Ferial E. Hubungan Antara Status Gizi Ibu Berdasarkan Ukuran Lingkar Lengan Atas (LILA) Dengan Berat Badan Lahir Bayi di RSUD Daya Kota Makassar. Jurnal Alam dan Lingkungan 2011;2(3):11-20.

17. Roland MCP, Friis CM, Voldner N, et al. Fetal Growth versus Birthweight: The Role of Placenta versus Other Determinants. Plos one. 2012;7(6):1-7.

18. Thureen PJ, Jr WWH. Neonatal Nutrition and Metabolism, 2 nd Ed, UK, Cambridge University Press, 2006, p1-31. 